\title{
Achieving High Selectivity and Facile Displacement with a New Thiol Auxiliary for Boron Mediated Aldol Reactions
}

Sandra Fanjul, Alison N. Hulme, ${ }^{\star}$ John W. White

School of Chemistry, The University of Edinburgh, West Mains Road, Edinburgh, EH9 3JJ, UK.

Supporting Information (Spectra)

Preparation of thiol auxiliary 1

Acylation and anti aldol reaction

Displacement reactions
S7-S16

S17-S25

S26-S35 
(1S,2R)-2-(N-mesitylenesulfonylamino)-1-phenyl-1-chloropropane 2

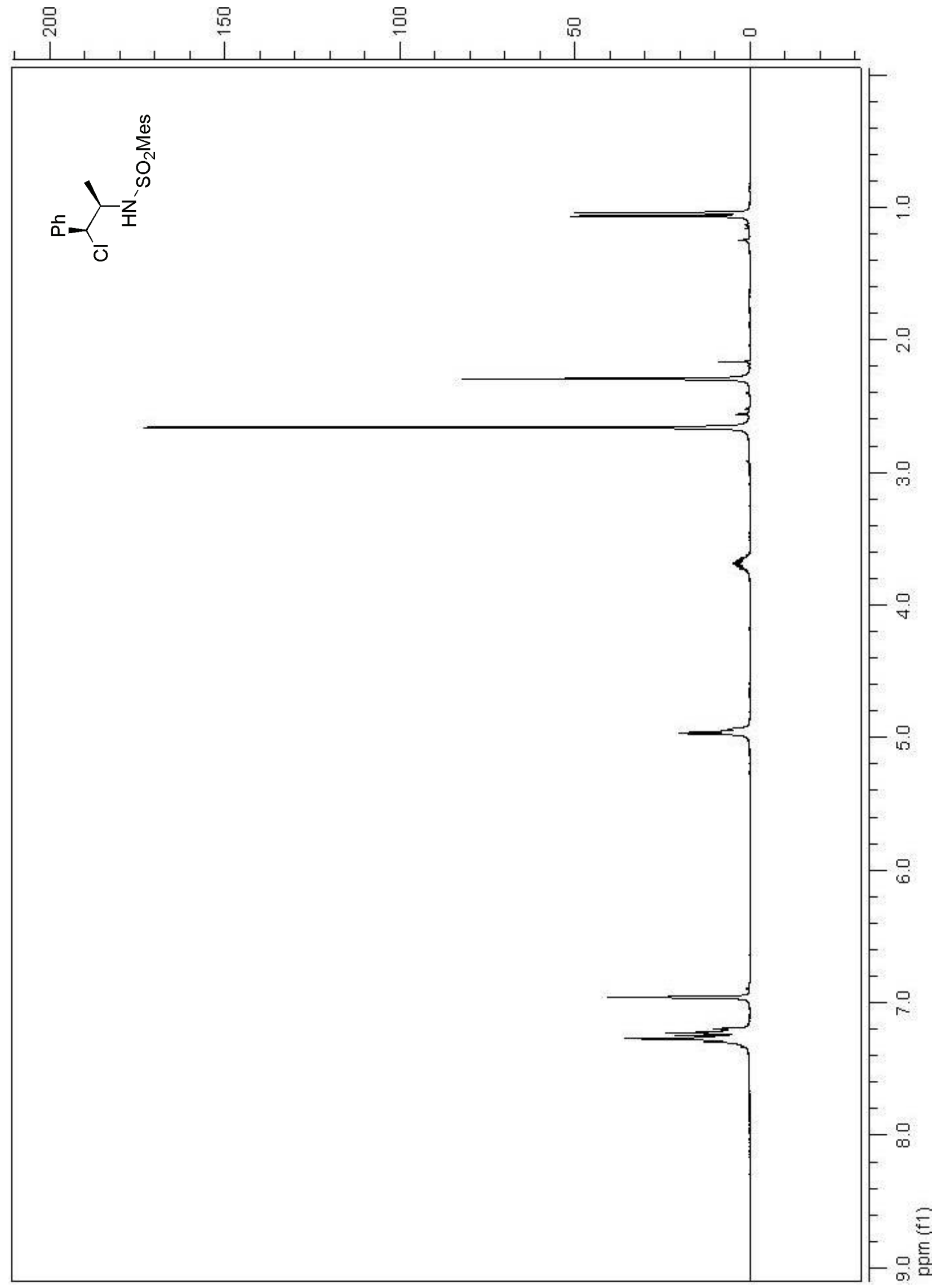




$$
7
$$


(2R,3R)-2-Methyl-3-phenyl-1-( $N$-mesitylenesulfonylamino)-aziridine 3

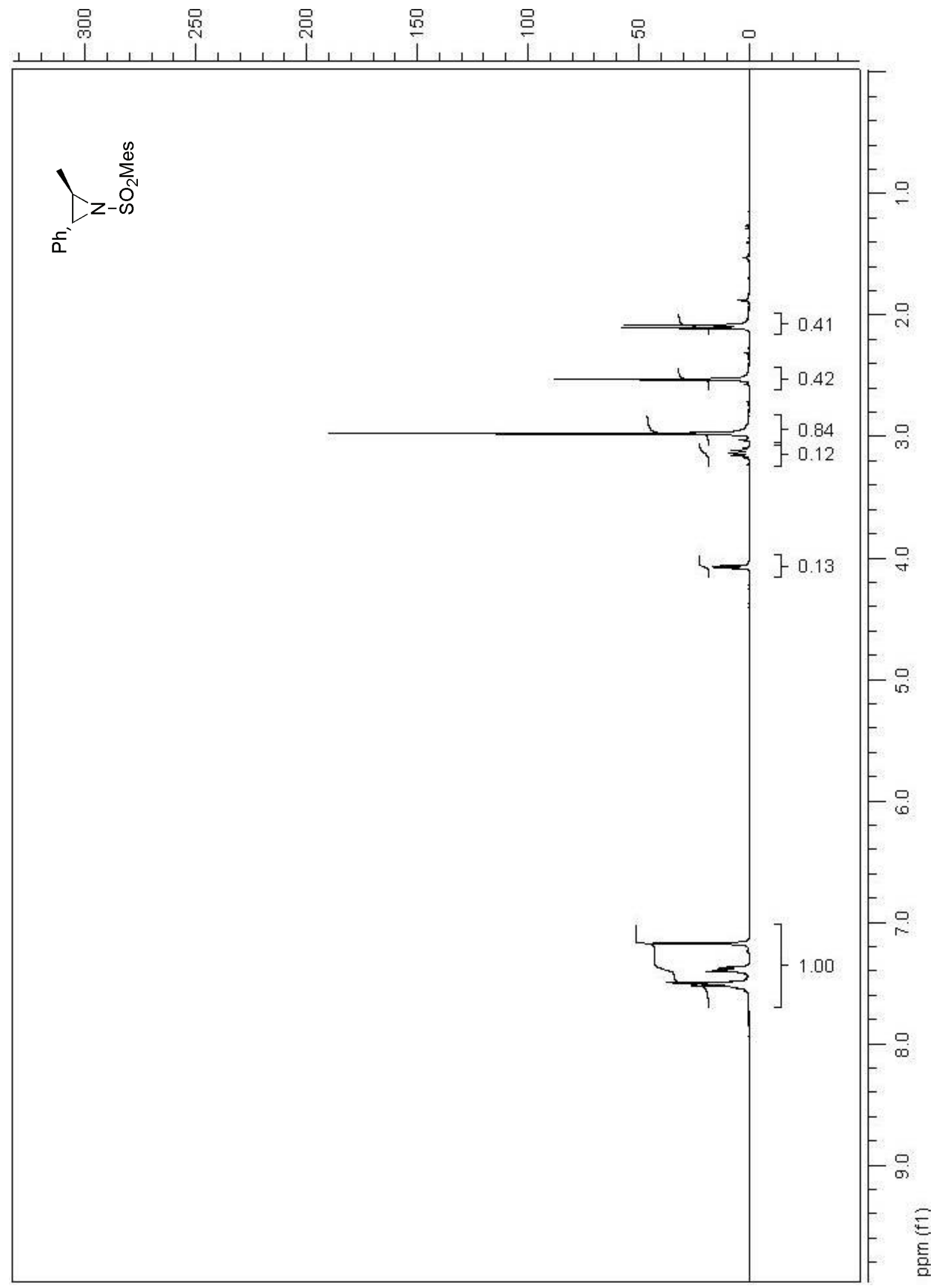




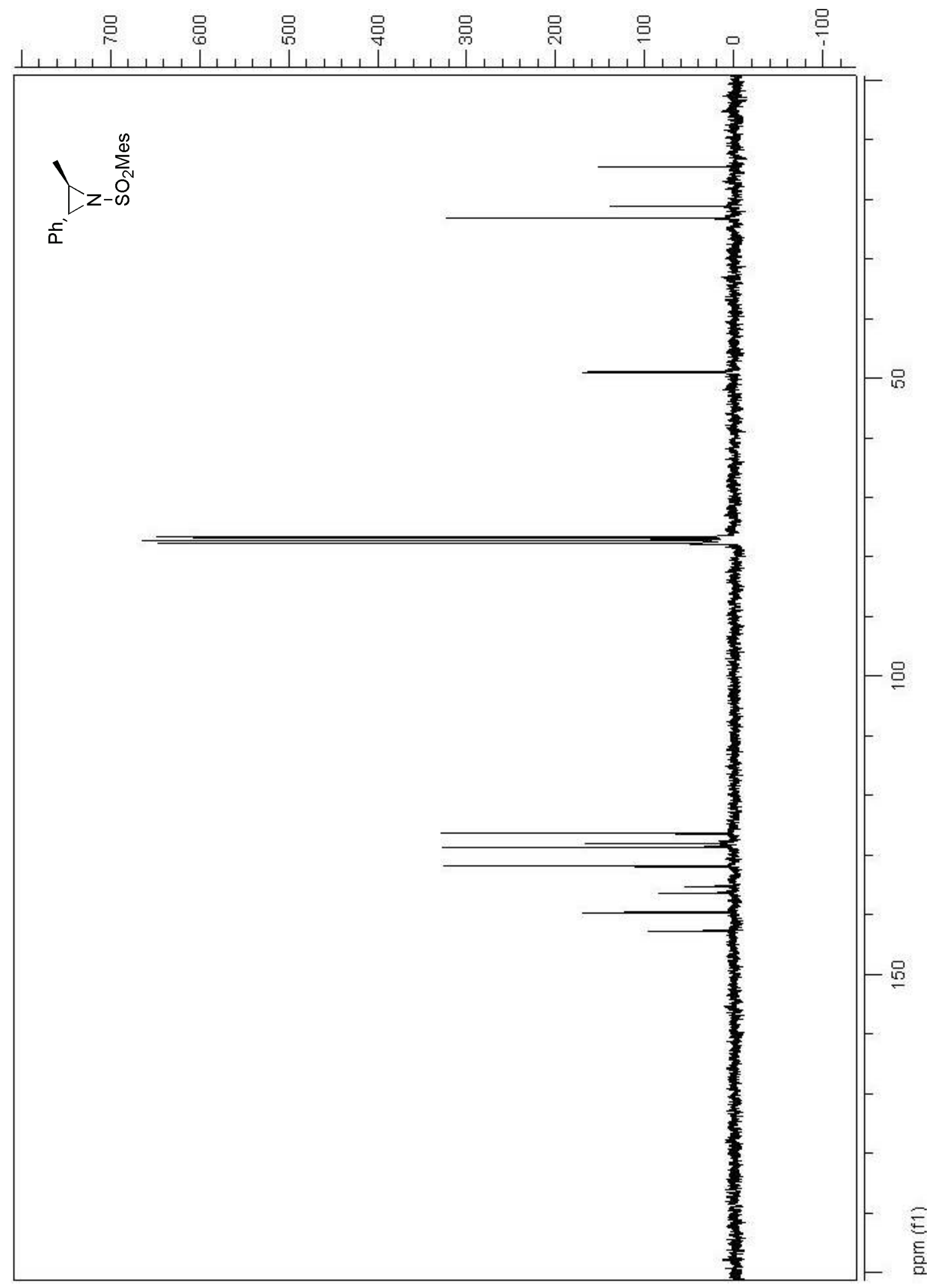

$-\mathrm{S} 10-$ 


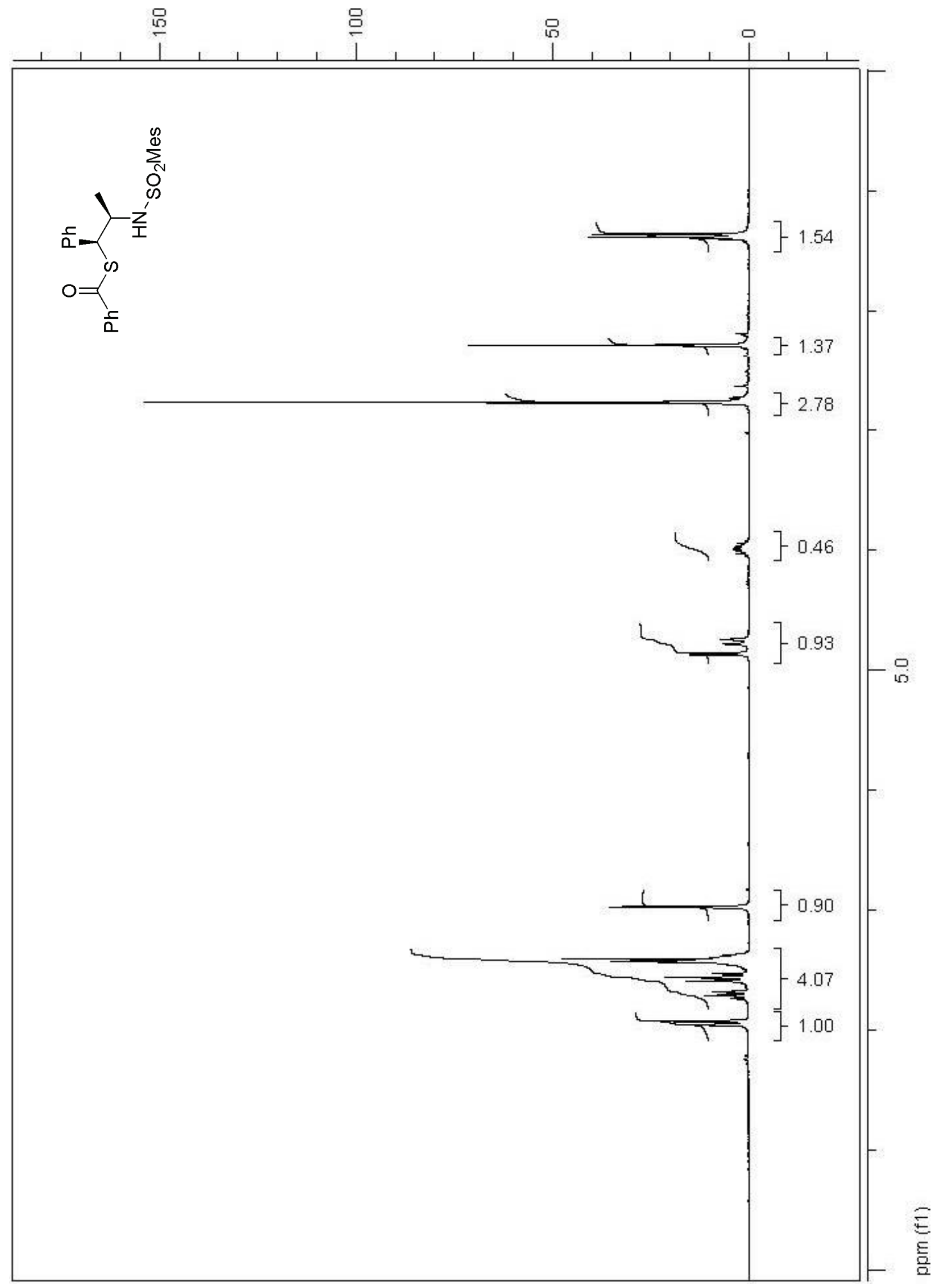




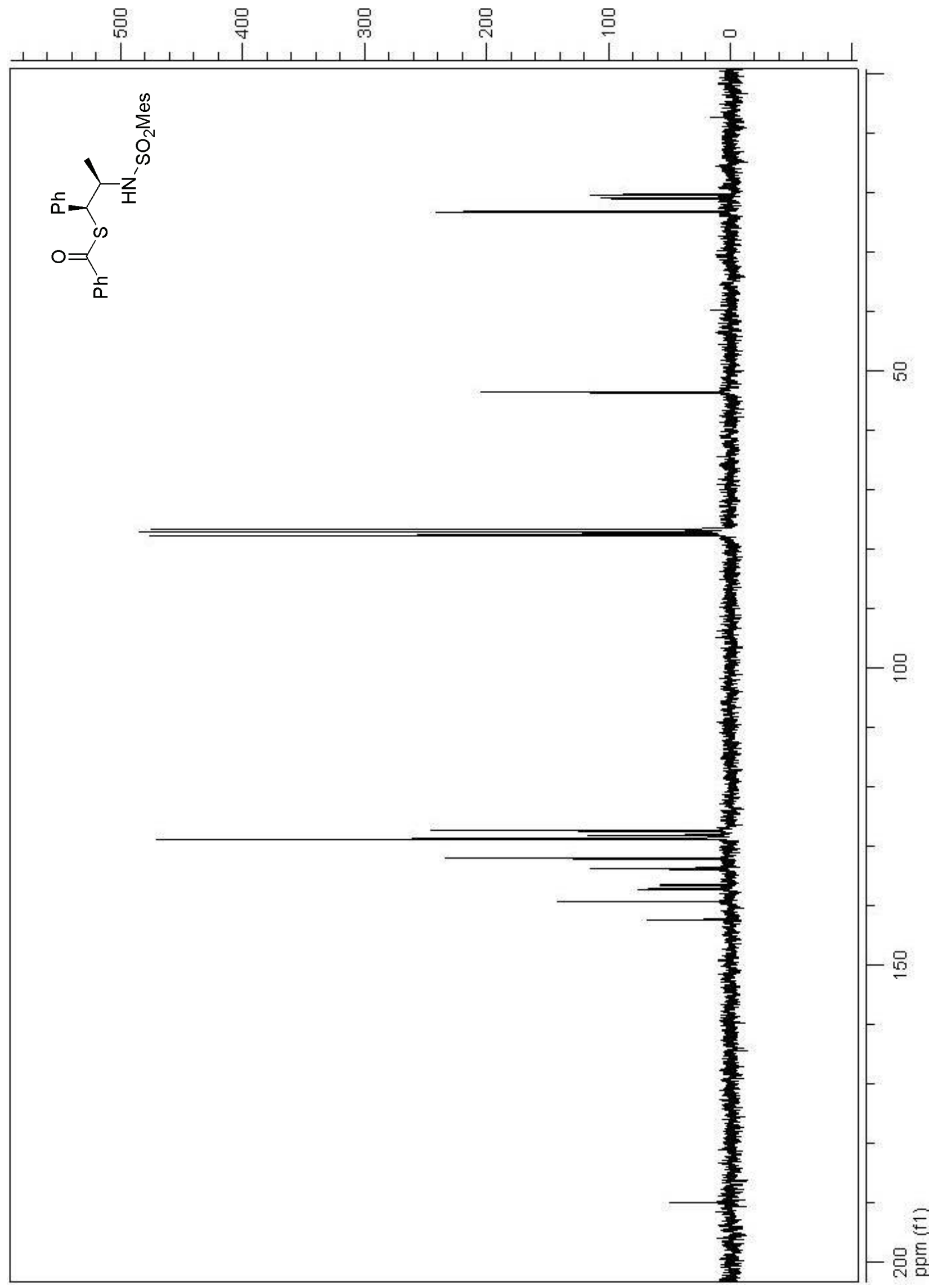

- S12 - 
(1'S,2'R)-2'-(N-Benzyl- $N$-mesitylenesulfonylamino)-1'-phenylpropyl thiolbenzoate 5

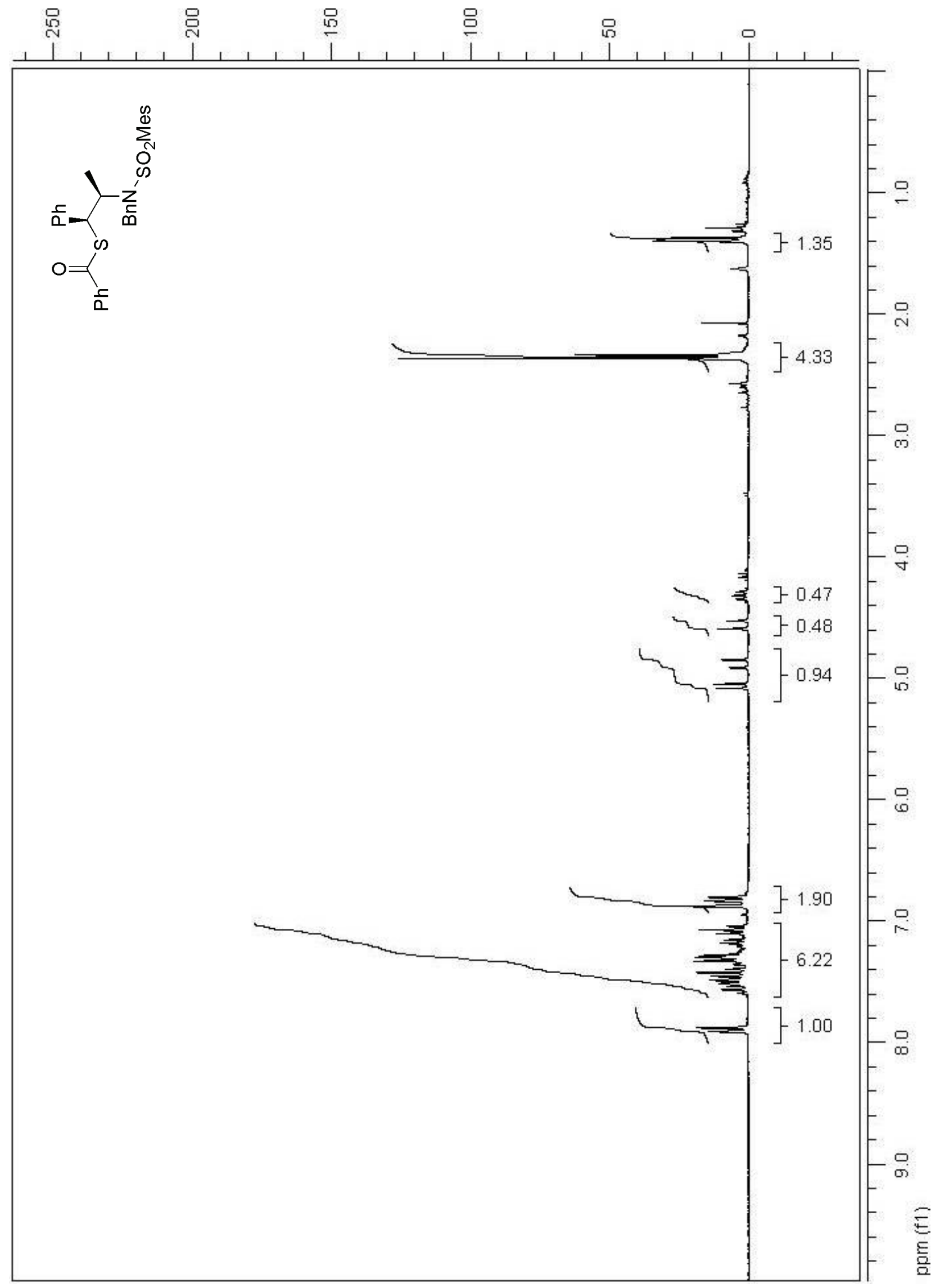




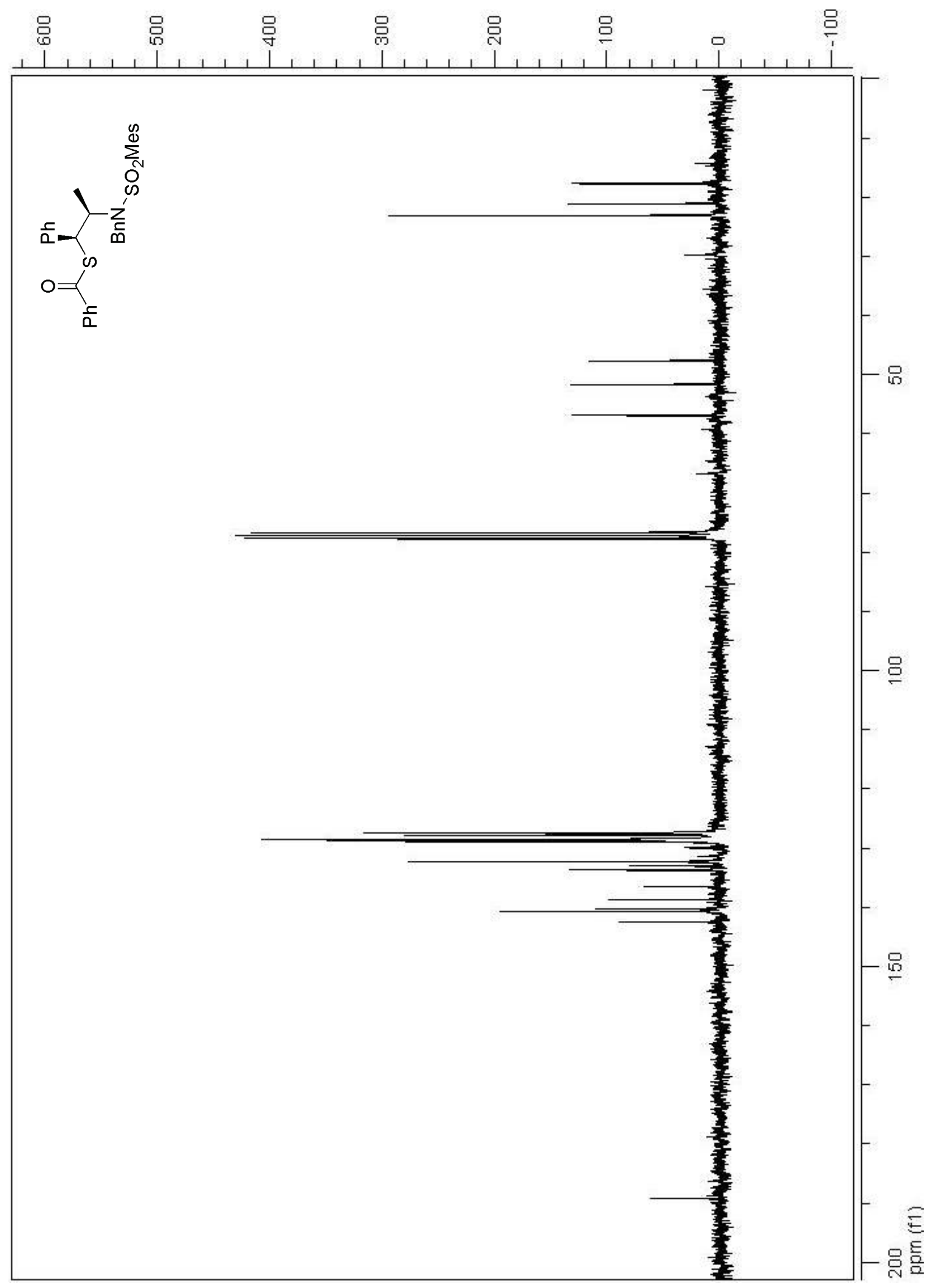

- S14 - 
(1S,2R)-2-( $N$-Benzyl- $N$-mesitylenesulfonylamino)-1-phenylpropane-1-thiol 1

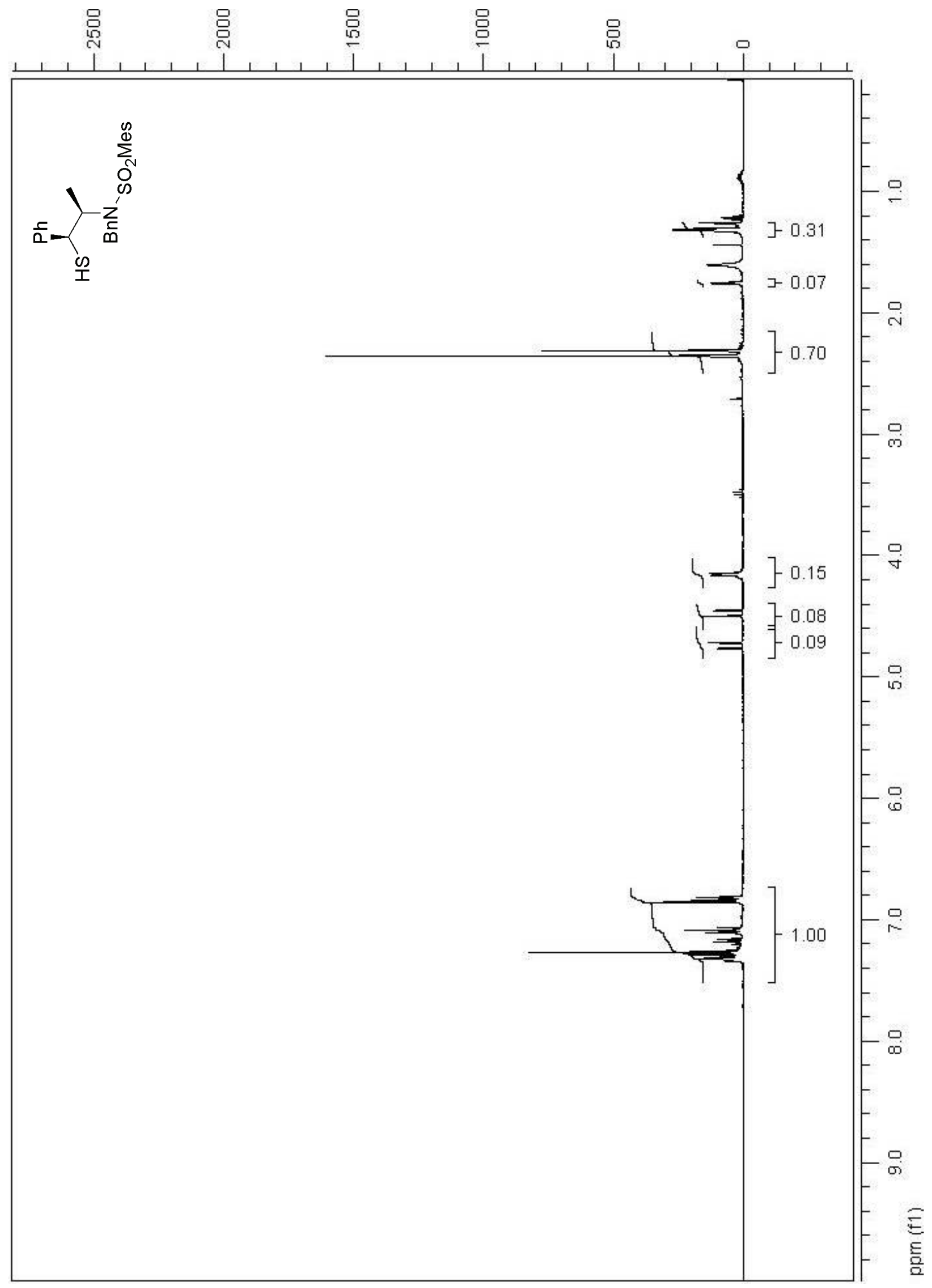




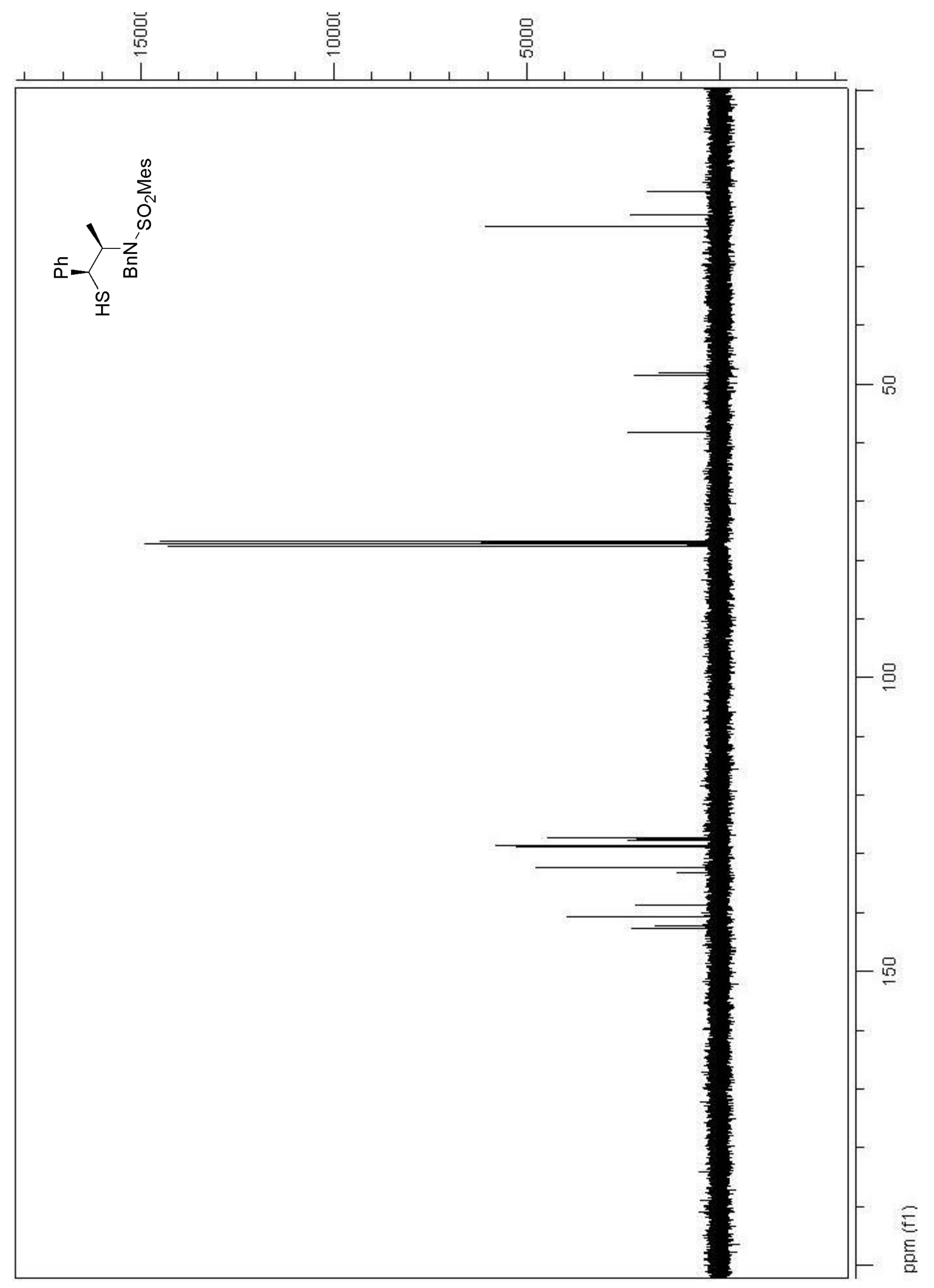

- S16- 
(1'S,2'R)-2'-(N-Benzyl- $N$-mesitylenesulfonylamino)-1'-phenylpropyl thiolpropionate 6

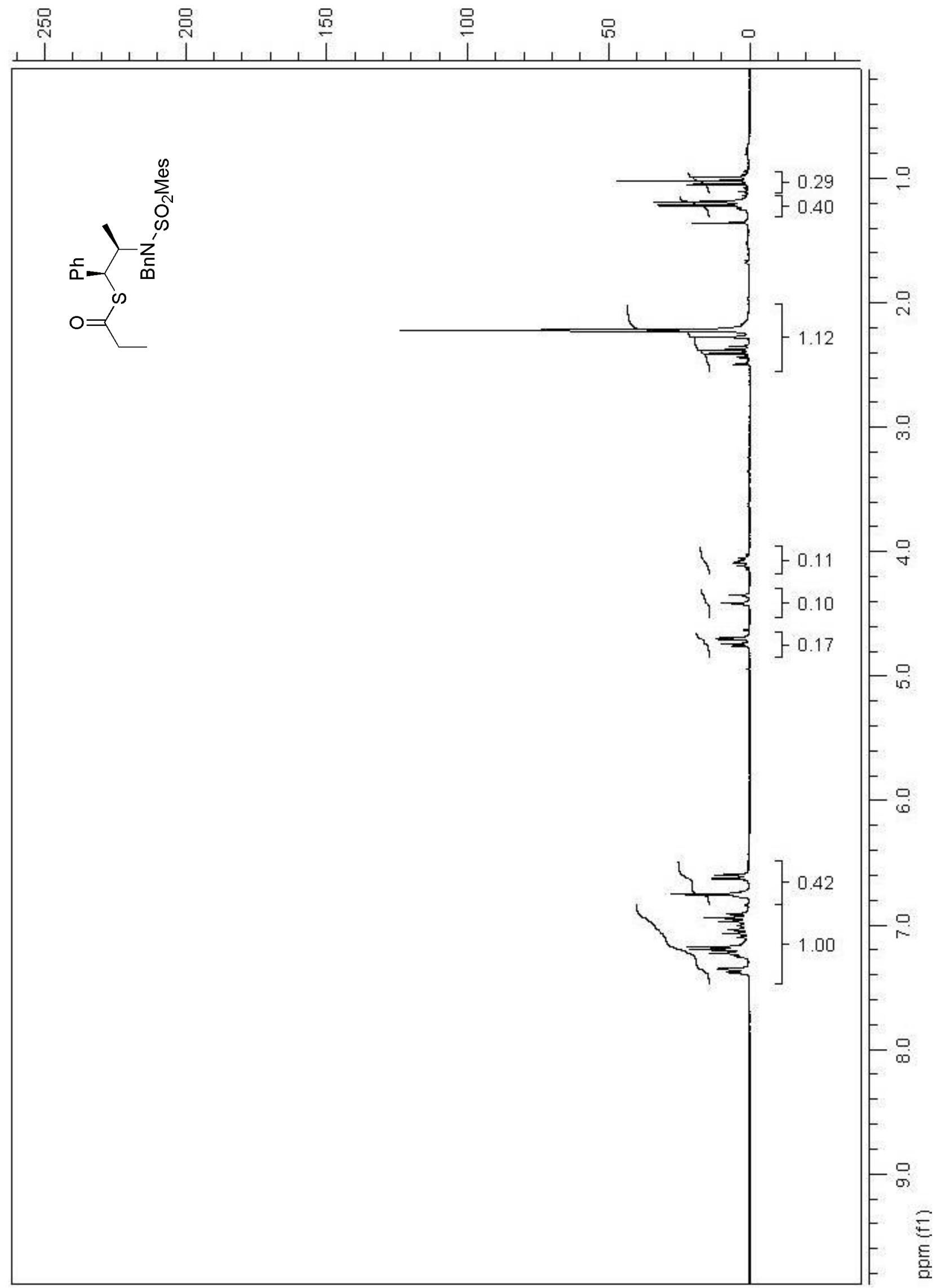




$$
7
$$




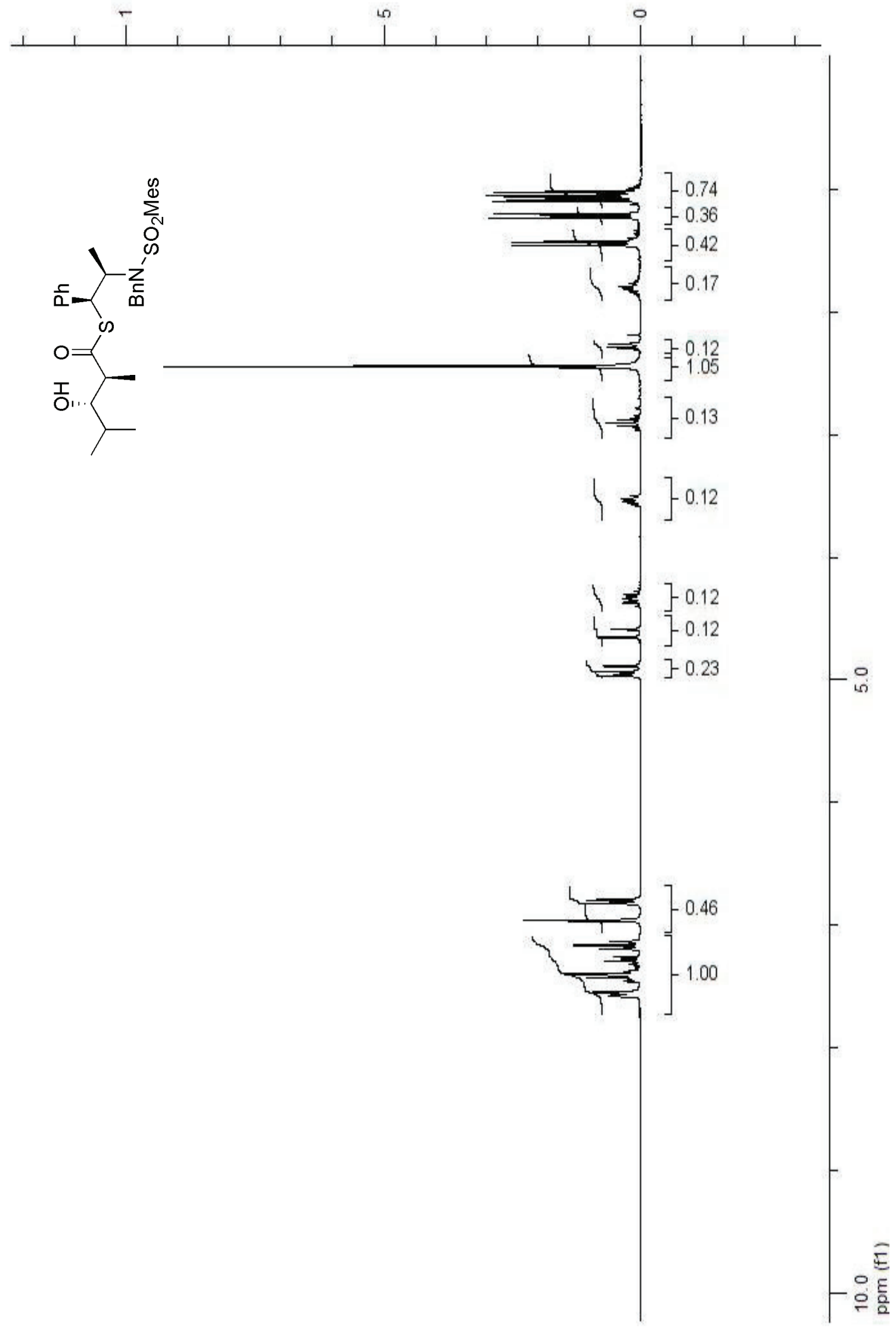




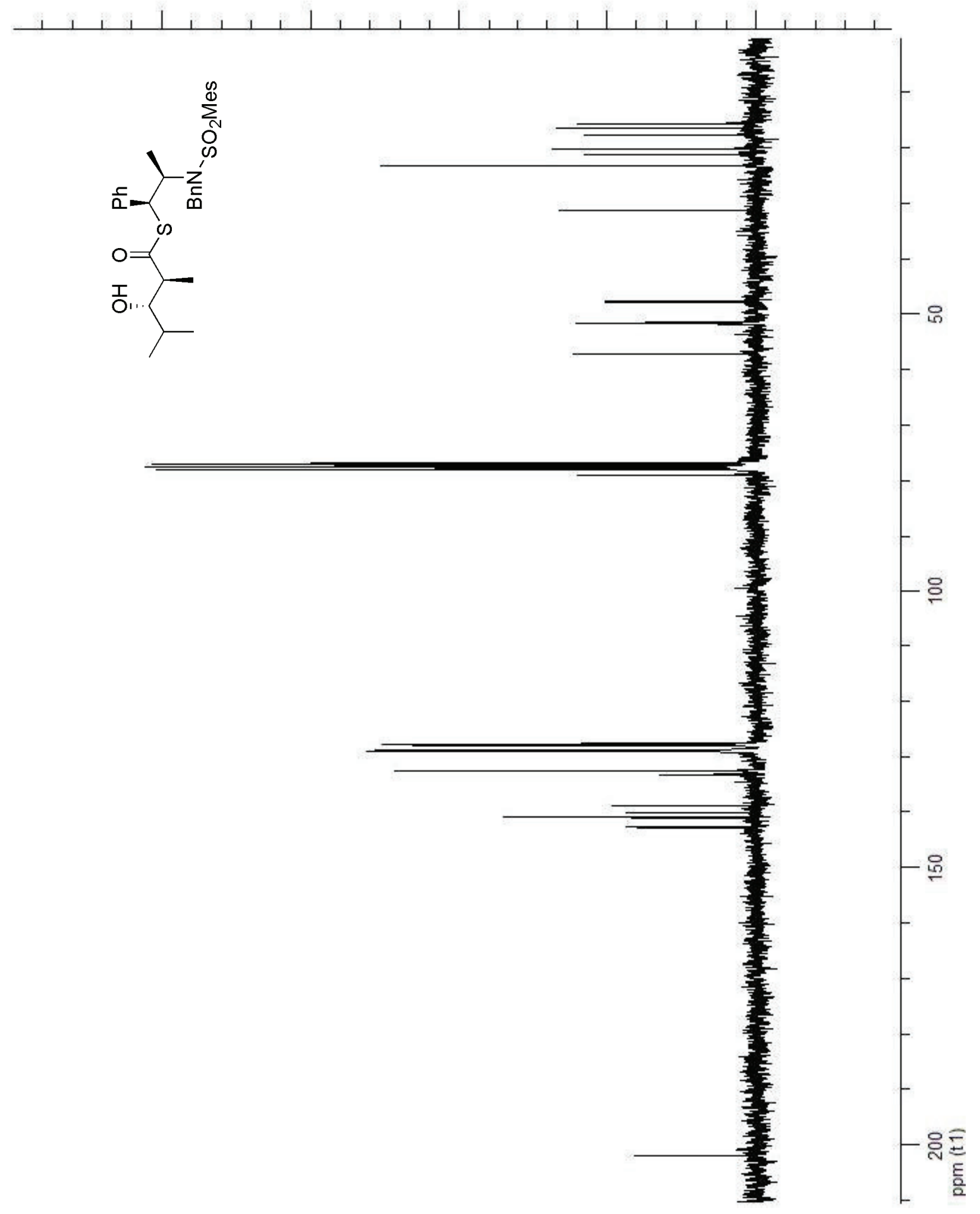

- S20 - 

minor diastereomer

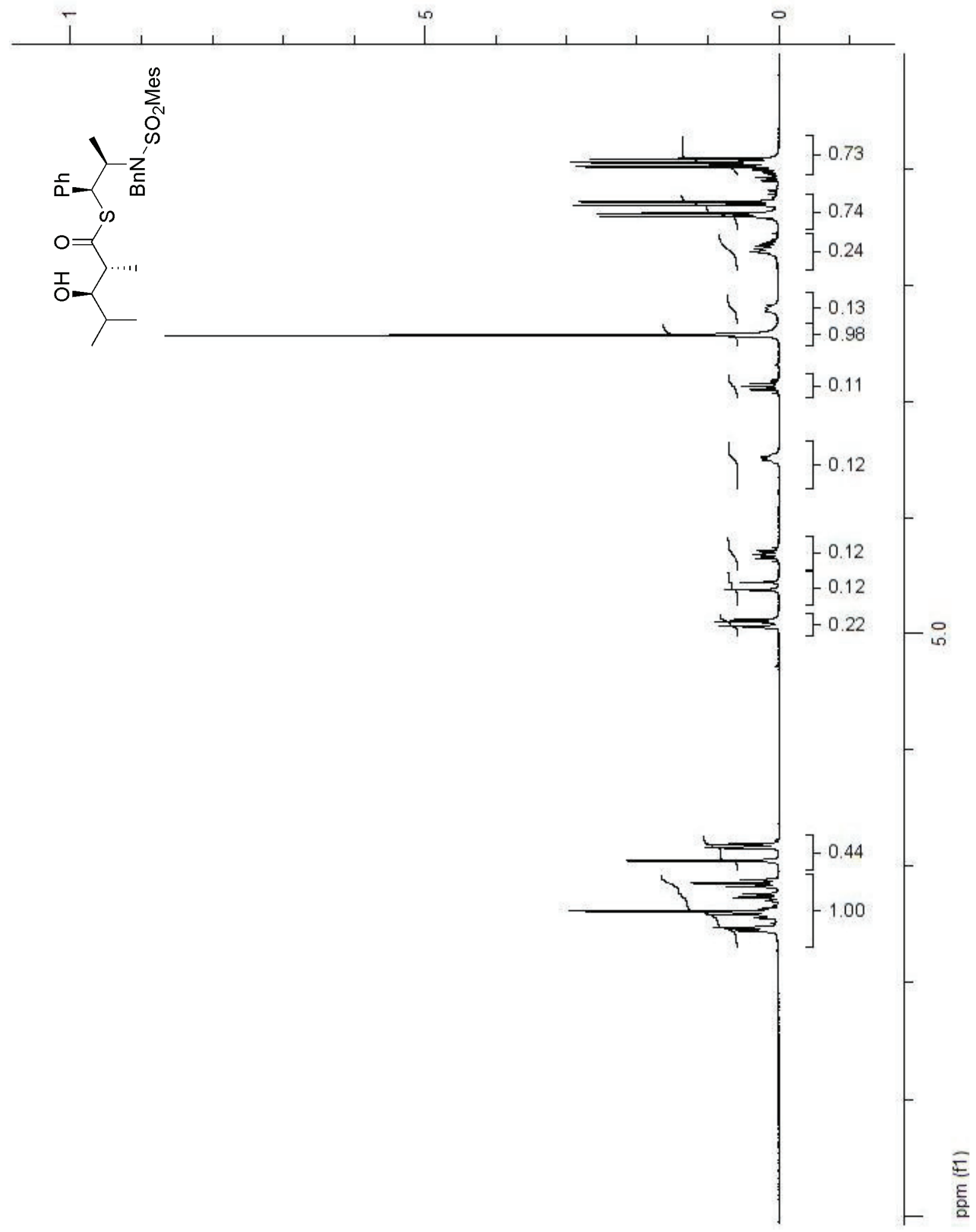


2'-(N-Benzyl- $N$-mesitylenesulfonylamino)-1'-phenylpropyl (1'S,2S,2' $R, 3 R)$-2,4-dimethyl-3-hydroxythiolpent-4eneoate $7 \mathrm{~b}$

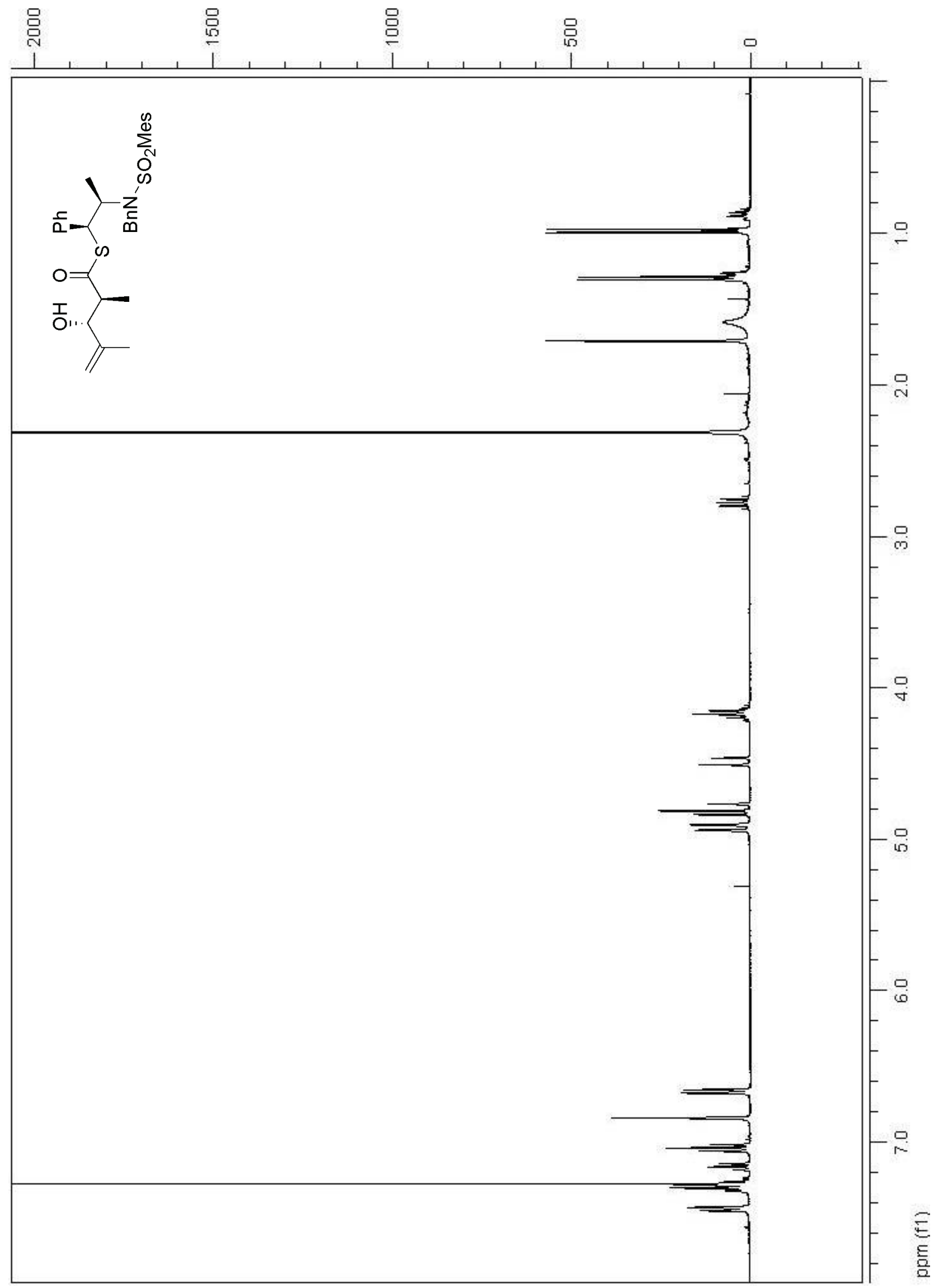




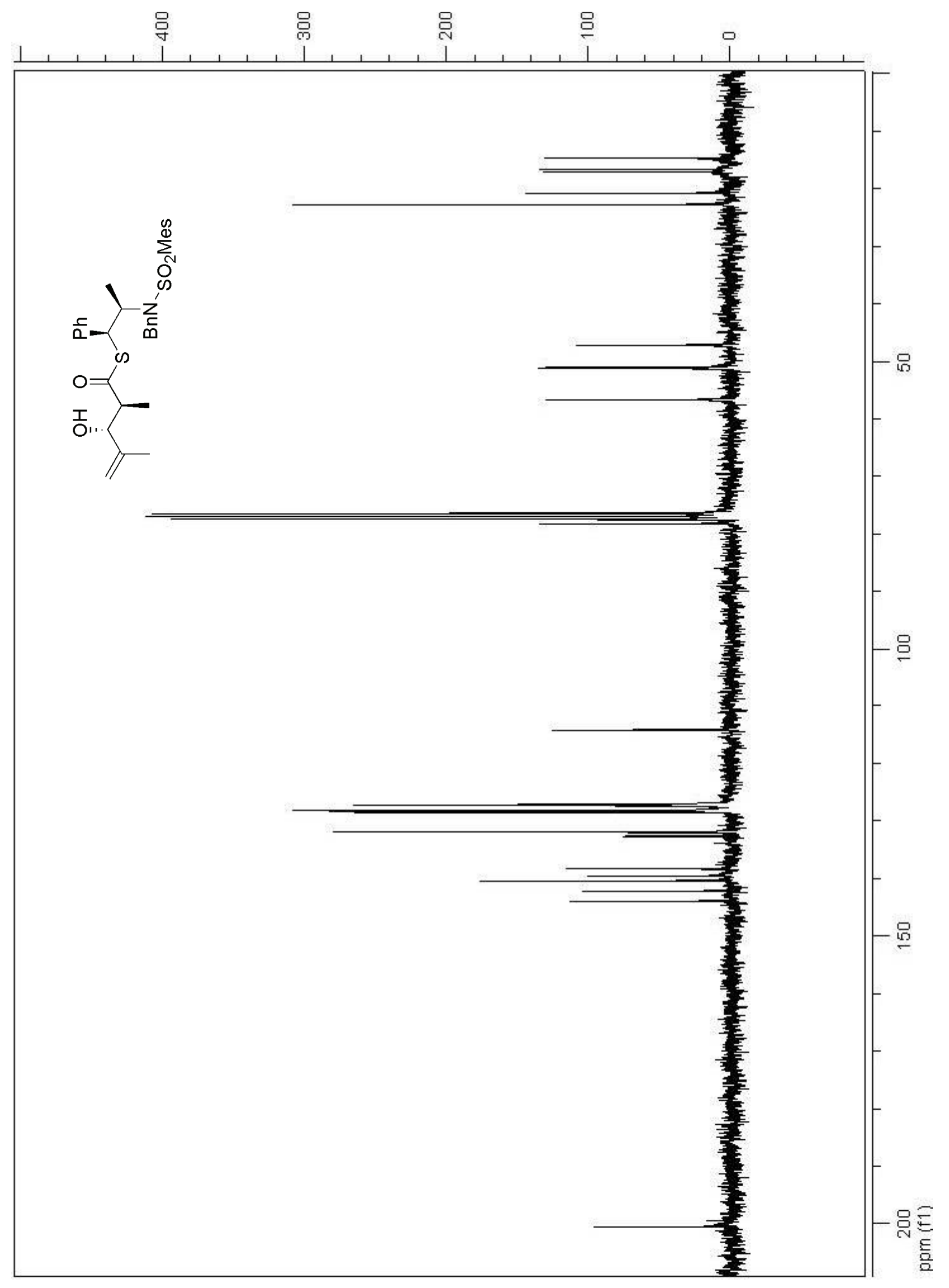

- S23 - 
2'-(N-Benzyl- $N$-mesitylenesulfonylamino)-1'-phenylpropyl (1'S,2S,2'R,3R)-3-hydroxy-2-methyl-3-phenylthiolpropionate $7 \mathrm{e}$

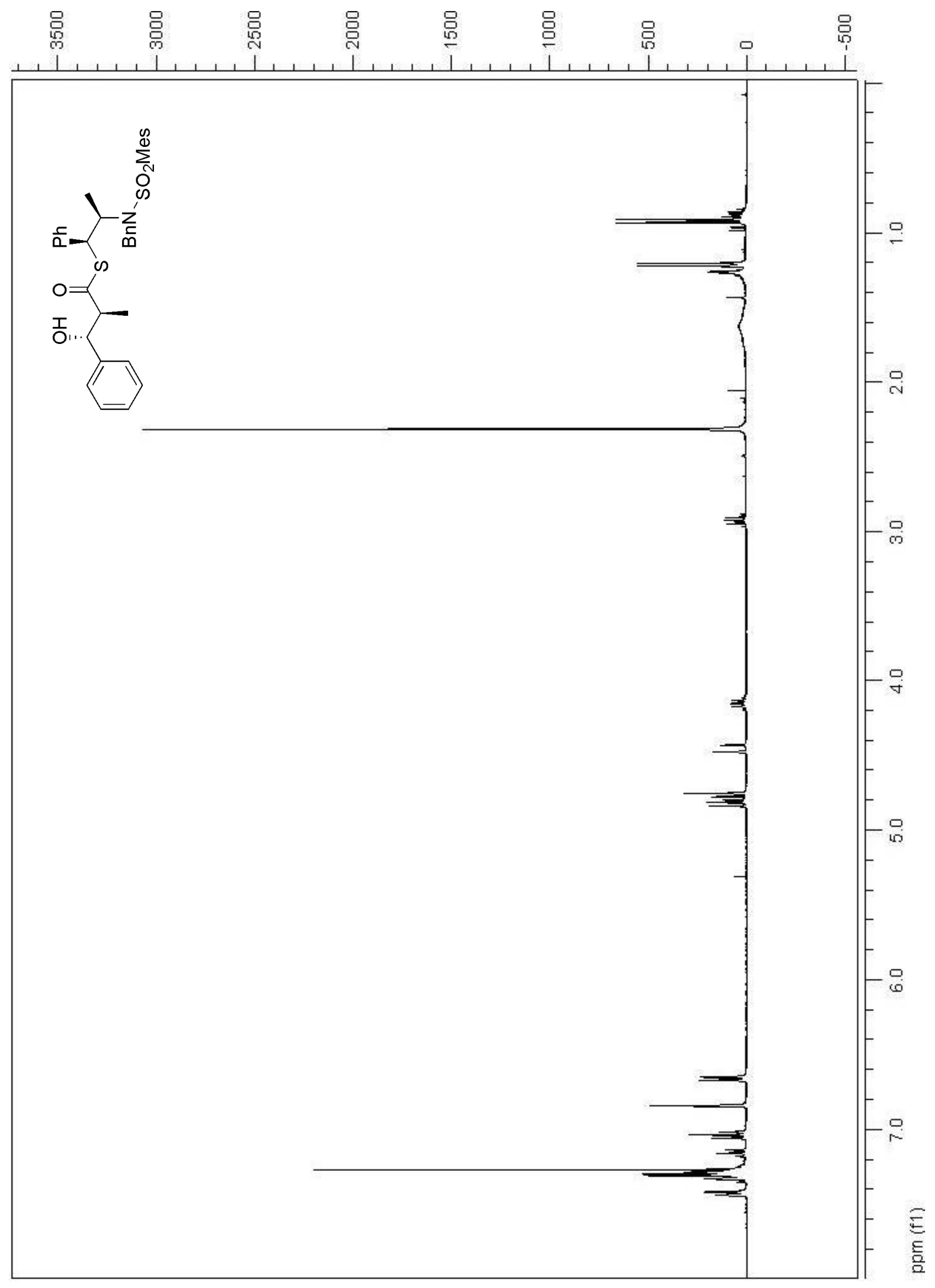




$$
4
$$




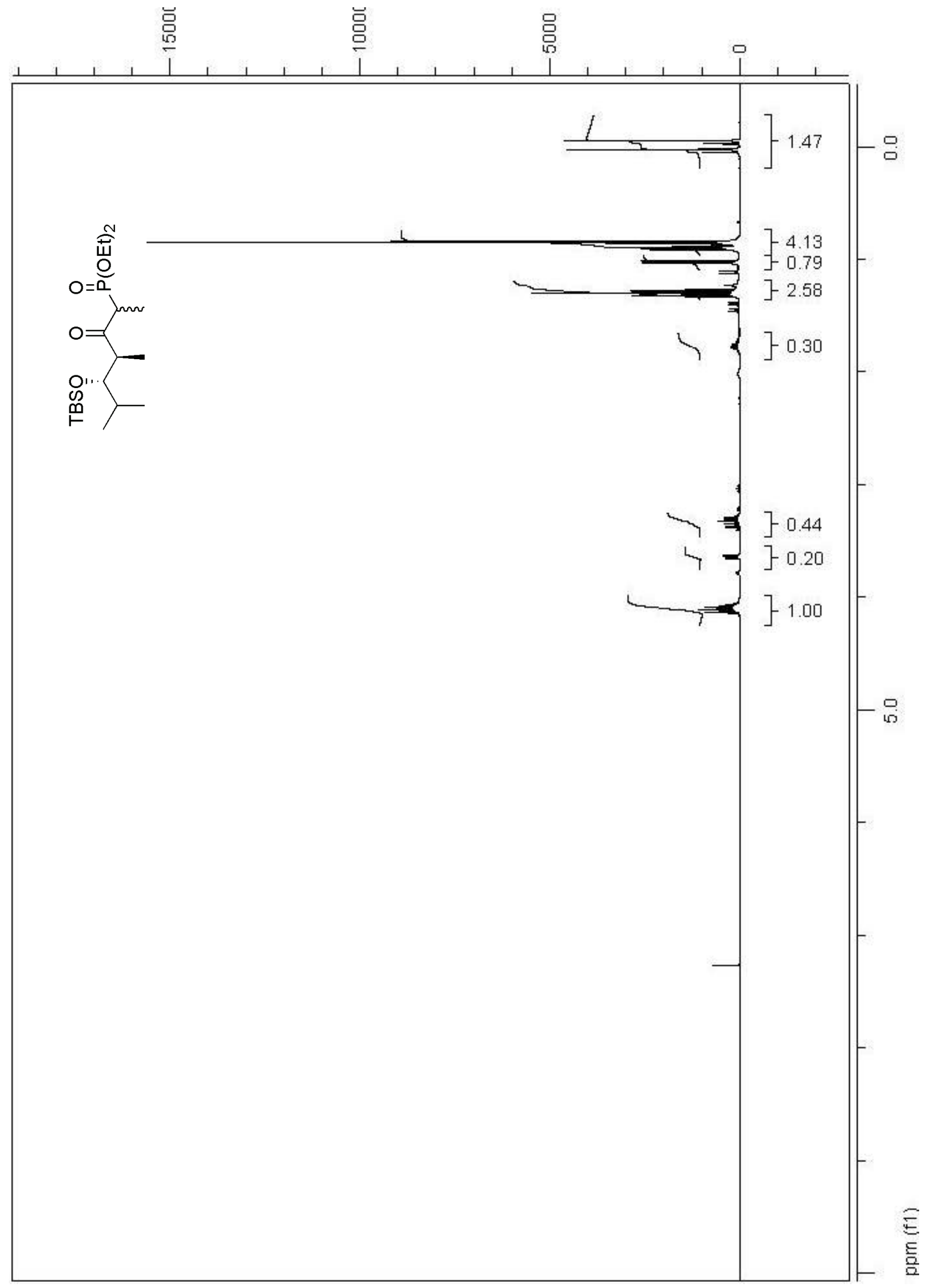




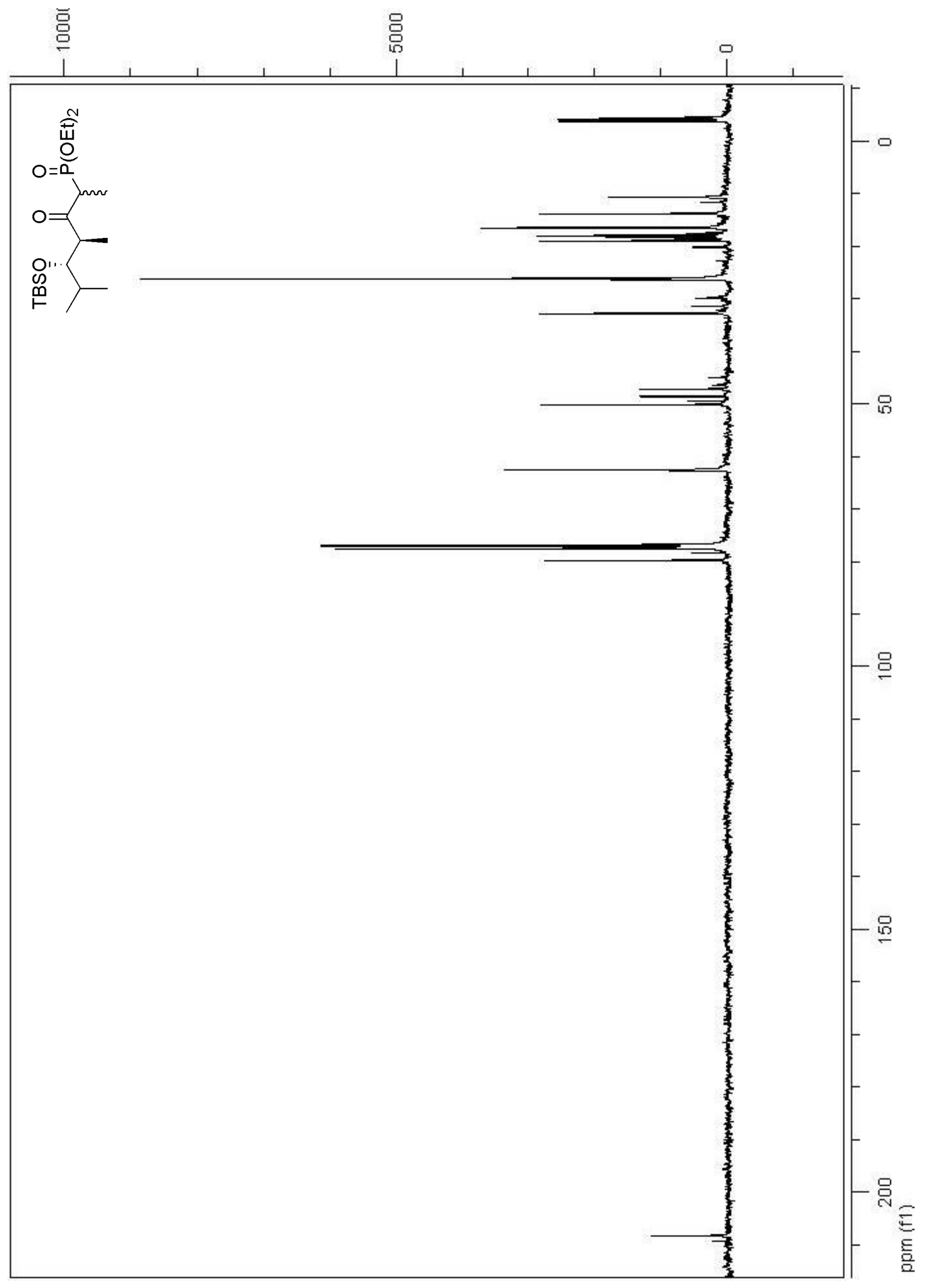

- S27 - 
(2R,3S)-2,4-Dimethylpentane-1,3-diol 10

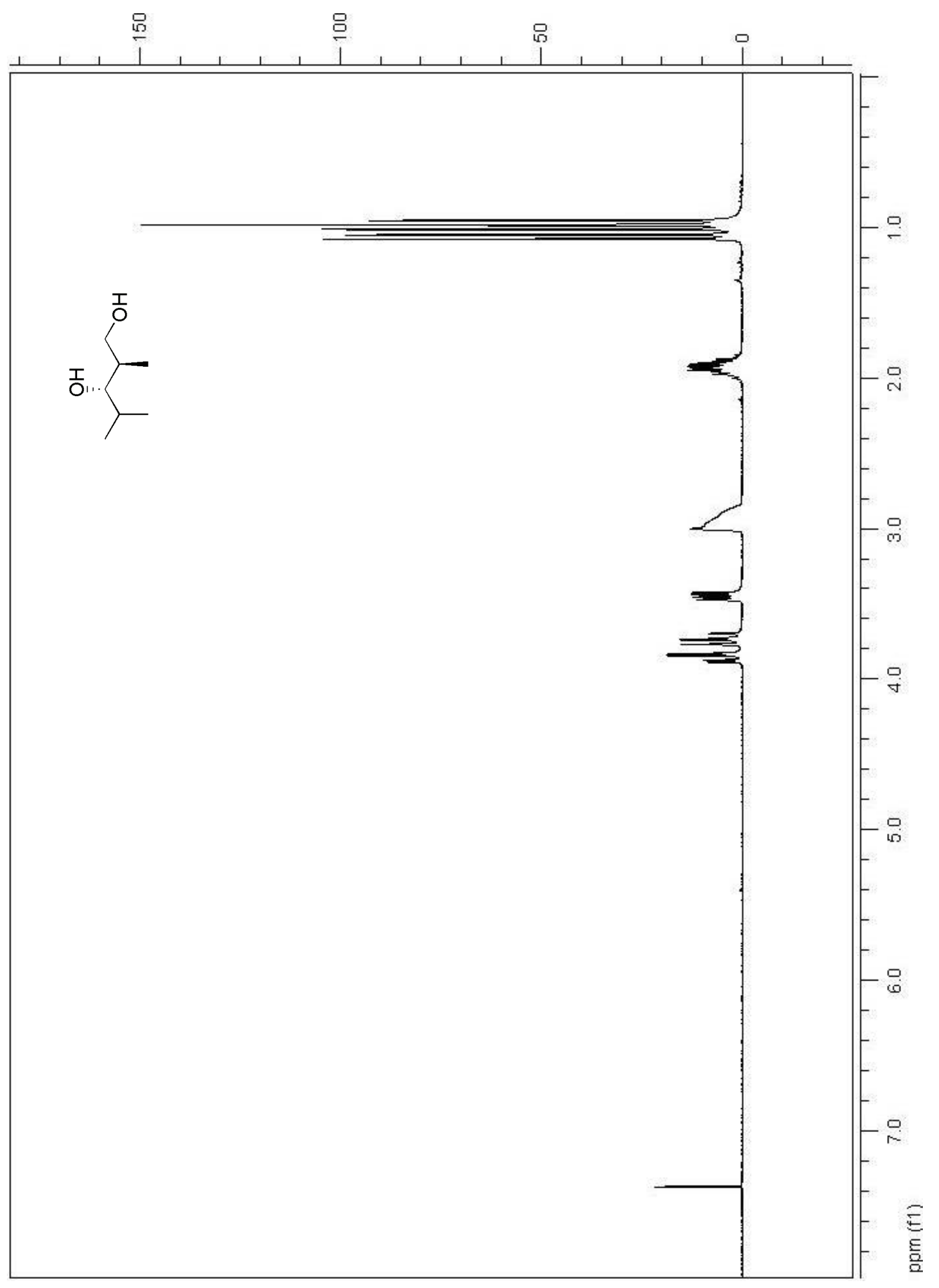

- S28 - 


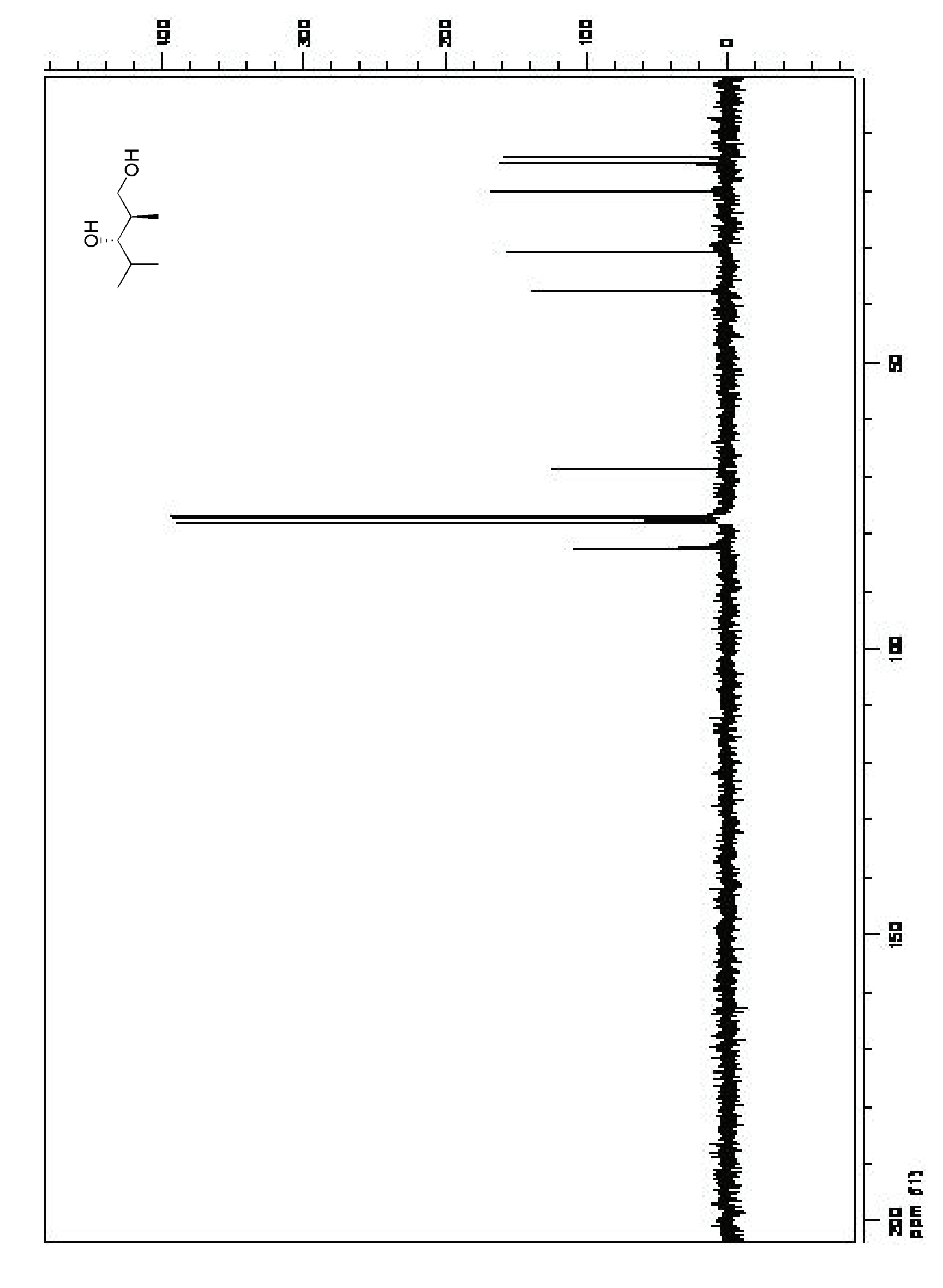




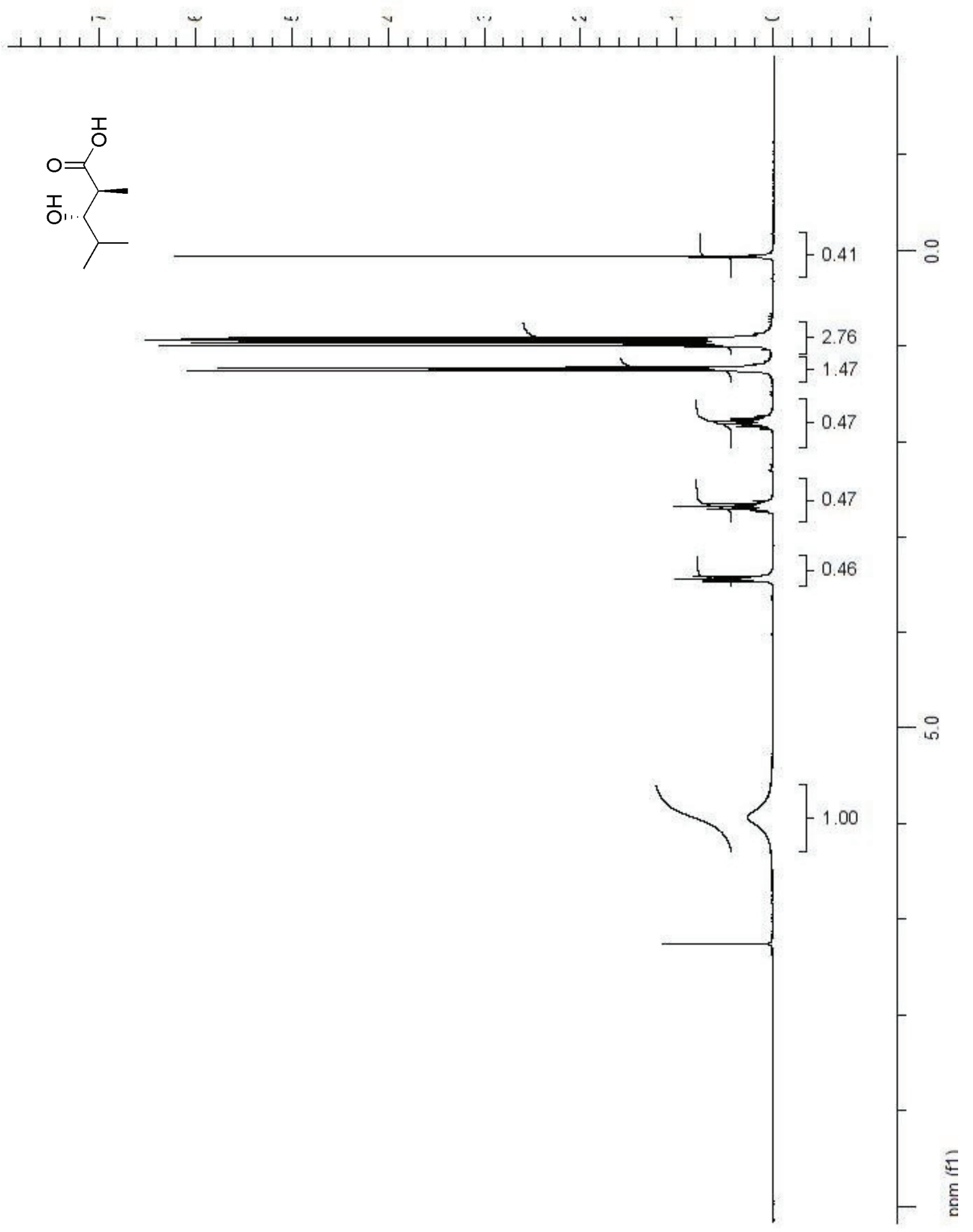




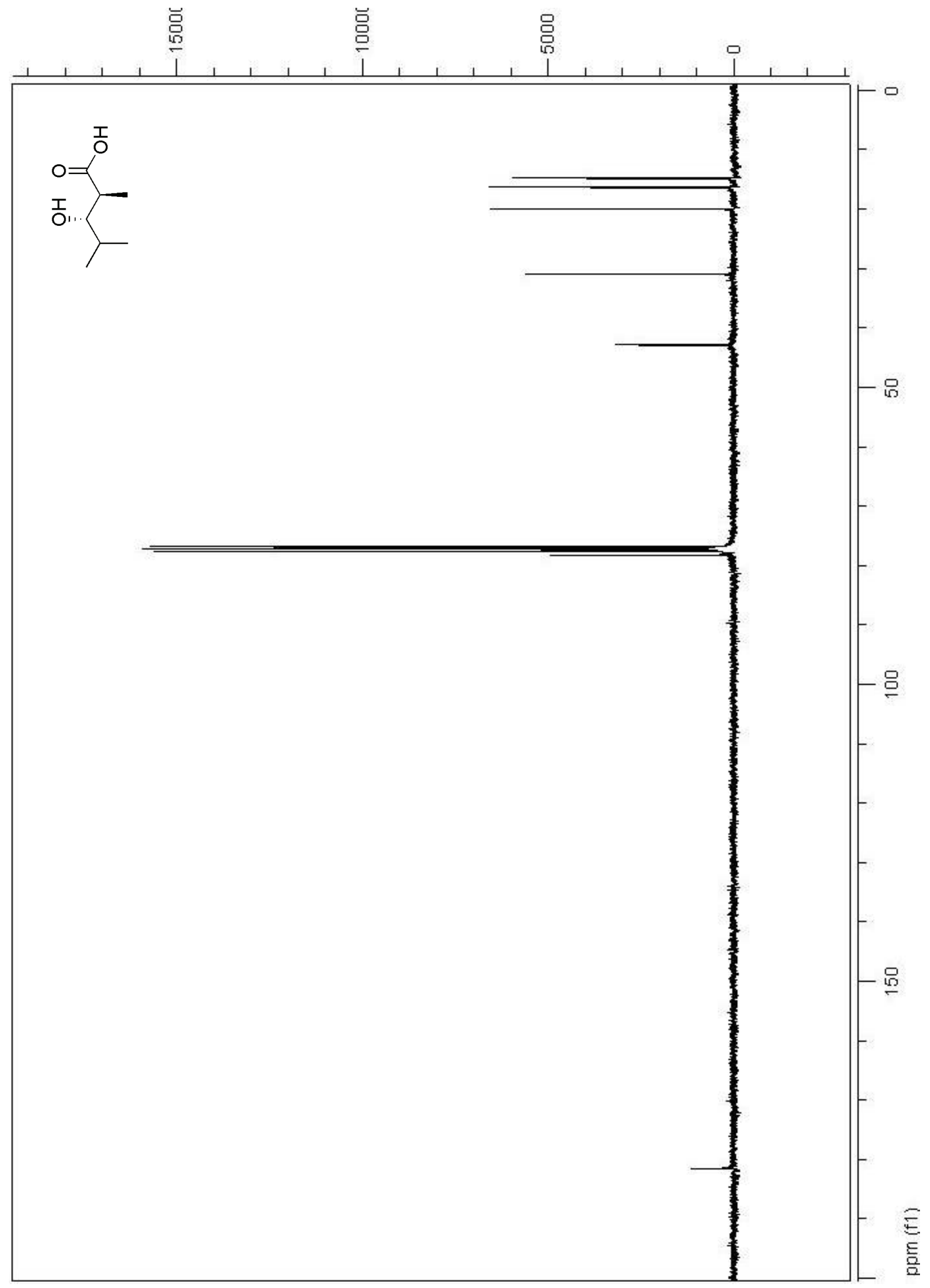

- S31 - 
2'-(Acetylamino)ethyl (2S,3S)-2,4-dimethyl-3-hydroxy-thiolpentanoate 12

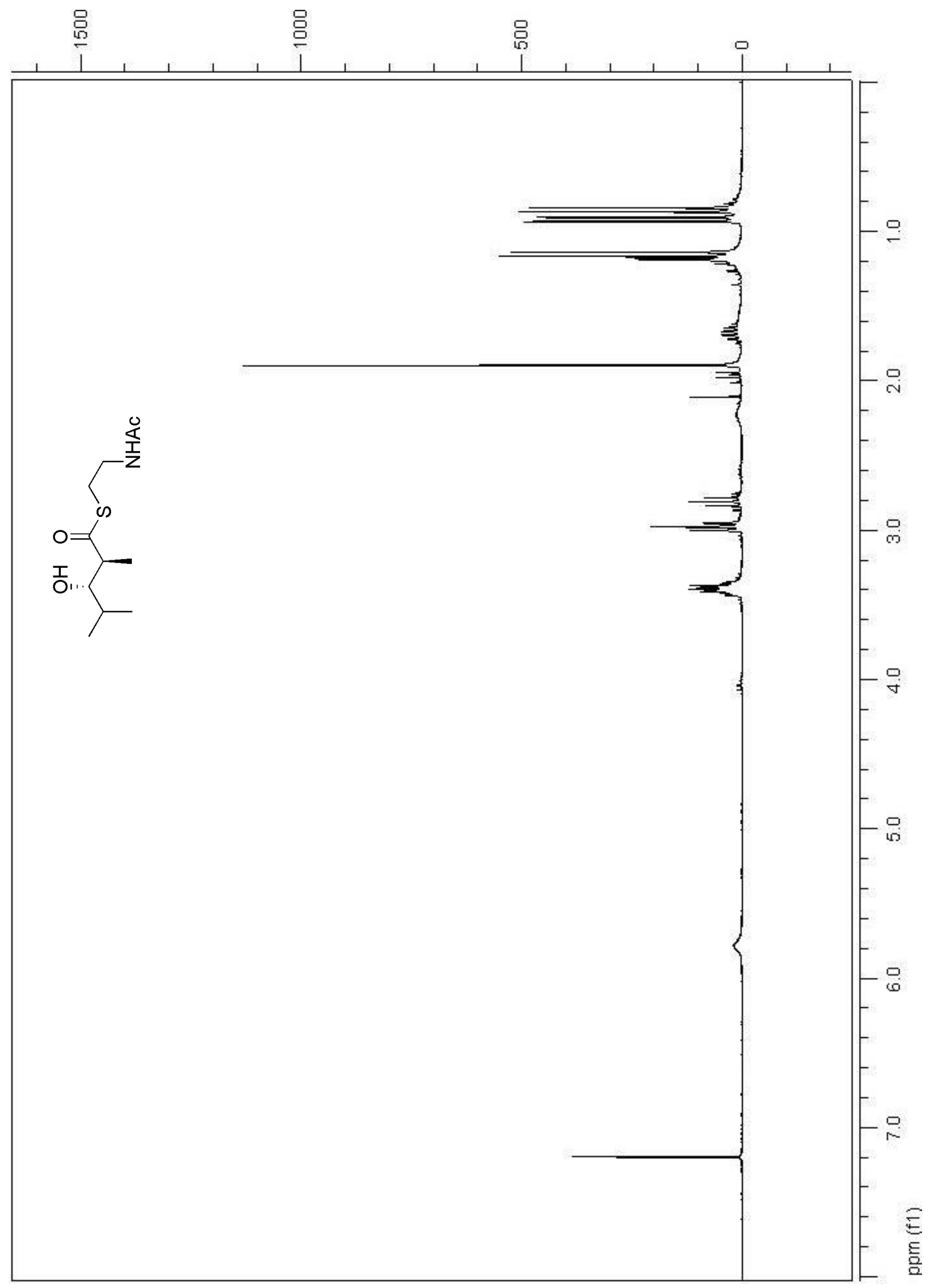




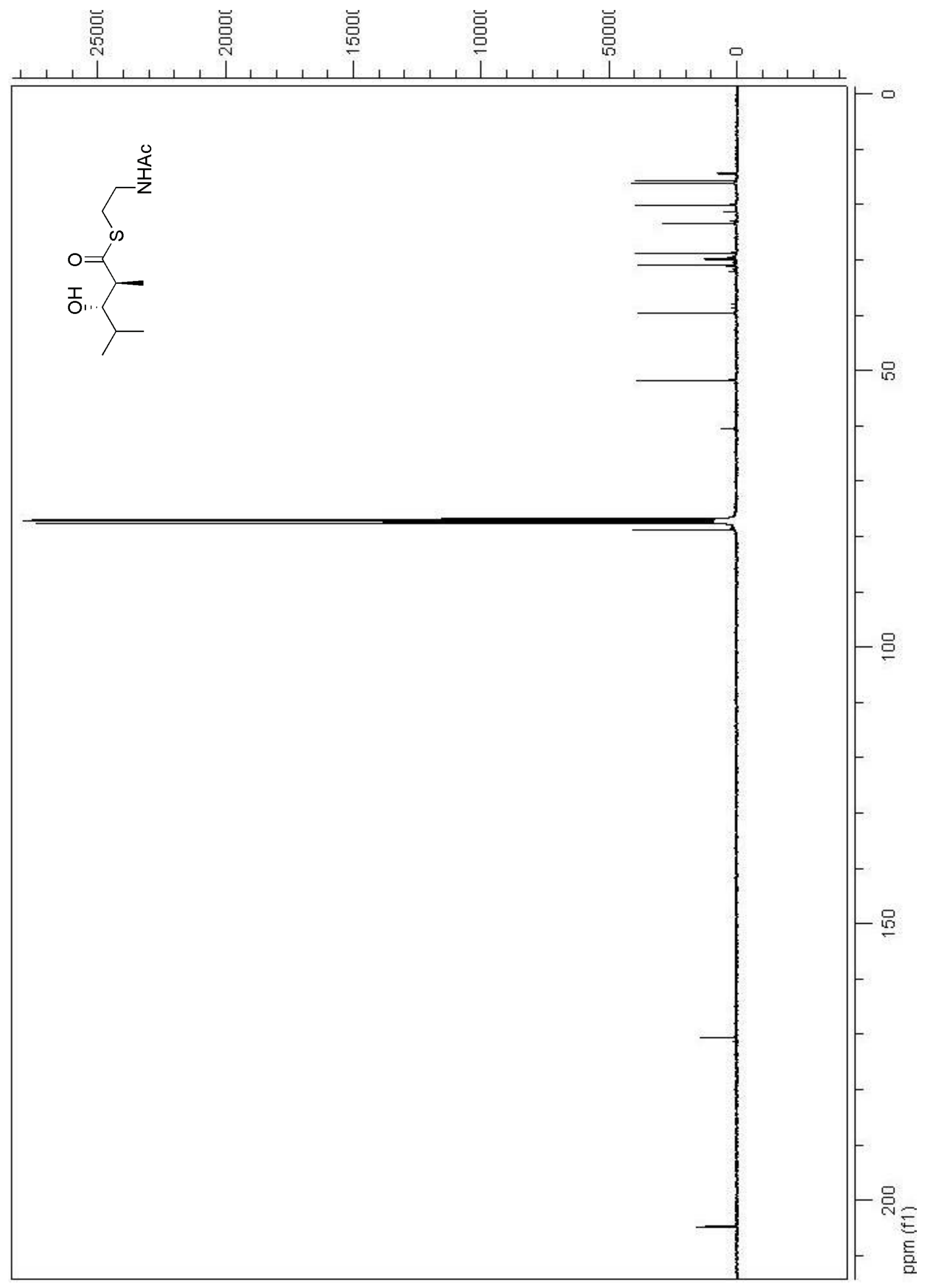

- S33 - 
Methyl (2S,3R)-3-hydroxy-2-methyl-3-piperonylpropanoate

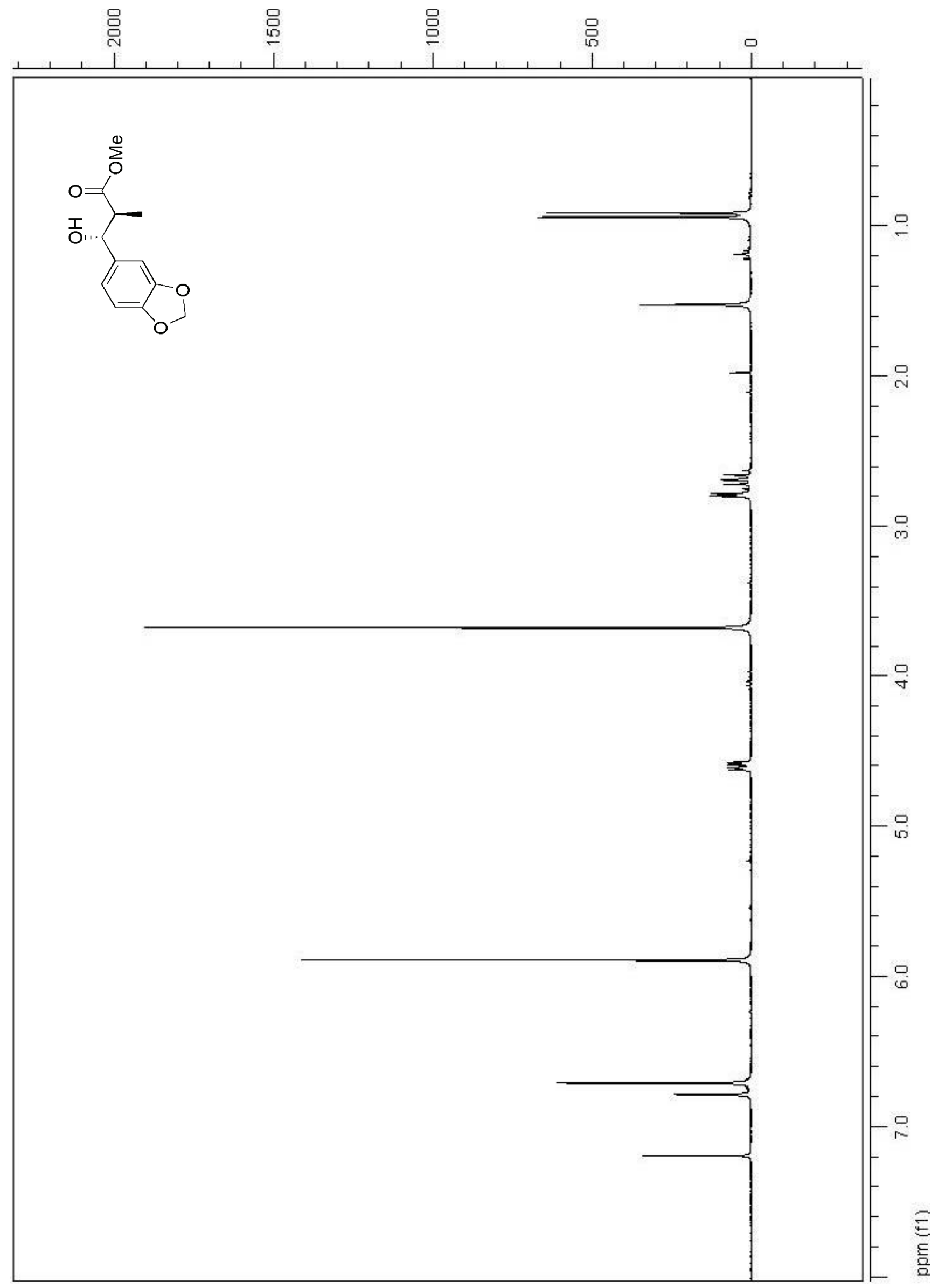




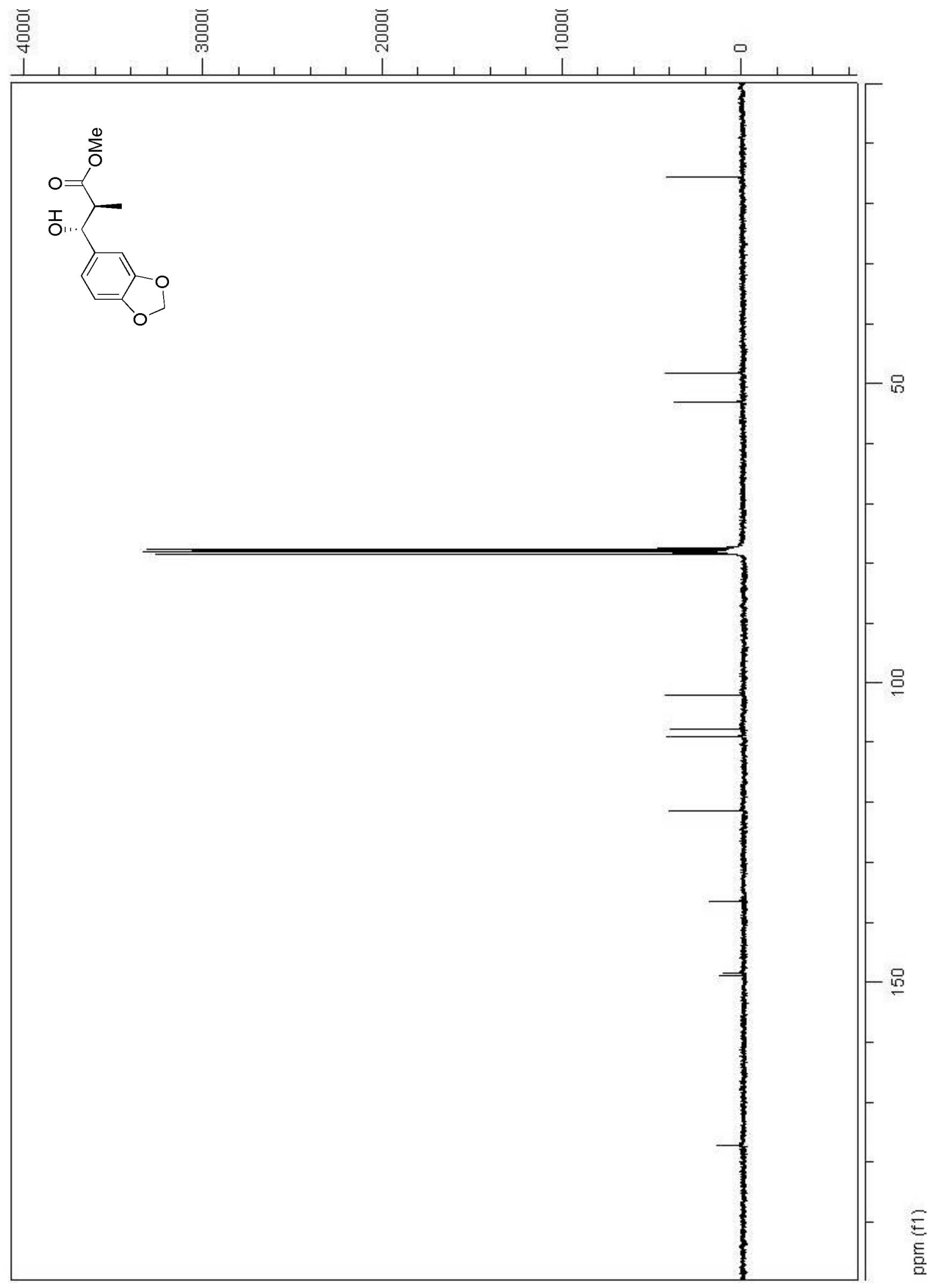

- S35 - 